Jurnal Kesehatan Karya Husada, Vol 9 No 1 Tahun 2021

PISSN 2337649X/EISSN 2655-8874

Endang Tri Sulistyowati"Penurunan Tingkat Stres Lansia dengan Senam Lansia di Dusun Mangir

Tengah Pajangan Bantul” (hal 74-90)

Received

Revisied

Acceptep

14 Desember 2020

24 Februari 2021

16 Juni 2021

\title{
PENURUNAN TINGKAT STRES LANSIA DENGAN SENAM LANSIA DI DUSUN MANGIR TENGAH PAJANGAN BANTUL
}

\author{
Endang Tri Sulistyowati \\ Prodi Promosi Kesehatan Politeknik Kesehatan Karya Husada Yogyakarta \\ Email: endangts80@gmail.com
}

\begin{abstract}
ABSTRAK
Latar belakang : Permasalahan yang sering dihadapi lansia seperti menurunnya daya tahan tubuh, mengalami berbagai penyakit degenerative dan permasalahan yang diterima dari lingkungan sekitar, maka tekanan pada diri lansia akan sangat berpengaruh pada timbulnya stres. Tujuan dari penelitian ini adalah untuk mengetahui pengaruh antara senam lansia dengan penurunan tingkat stres pada lansia. Metode Penelitian ini merupakan penelitian Quasy Experiment dengan desain one group pre-post test yang dilakukan diDusun Mangir Tengah kelurahan Sendangsari Pajangan Bantul. Metoda yang digunakan total sampling dengan subyek semua lansia di Dusun Mangir tengah yang bersedia menjadi subyek penelitian berjulah 34 orang. Hasil penelitian : Kegiatan senam lansia yang dilakukan secara bersama-sama di Dusun Mangir Tengah, Sendangsari, Pajangan, Bantul dapat menurunkan tingkat stress lansia setelah dilakukan secara rutin setiap minggu selama satu bulan. Penurunan tingkat stress lansia setelah melakukan senam lansia bersama sekitar 44 persen.Kesimpulan :Kegiatan senam lansia yang dilakukan secara bersama-sama di Dusun Mangir Tengah, Sendangsari, Pajangan, Bantul dapat menurunkan tingkat stress lansia.
\end{abstract}

Kata Kunci : Senam, tingkat stres, lansia

\begin{abstract}
Background : problems that are often faced by the elderly, such as decreased endurance, experiencing various degenerative diseases and problems received from the surrounding environment, the stress on the elderly will greatly affect the emergence of stress. Destination The purpose of this study was to determine the effect of exercise in the elderly with a reduction in stress levels in the elderly. Method This research is a pre-experimental study with a one group pre-post test design which was conducted in Mangir Tengah hamlet, Sendangsari Pajangan village, Bantul. The method used was total sampling with 34 people as the subject of all elderly people in Dusun Mangir Tengah who were willing to become research subjects. Research result Elderly exercise activities carried out together in the village of Mangr Tengah
\end{abstract}


Jurnal Kesehatan Karya Husada, Vol 9 No 1 Tahun 2021

PISSN 2337649X/EISSN 2655-8874

Endang Tri Sulistyowati“Penurunan Tingkat Stres Lansia dengan Senam Lansia di Dusun Mangir

Tengah Pajangan Bantul" (hal 74-90)

with display of Bantul displays can reduce the stress level of the elderly after being routinely done every week for one month.decreased stress levels of the elderly after doing elderly gymnastics together around 44 percent. Conclusion Elderly gymnastics activities carried out together in the middle of Mangir Tengah hamlet spring Sendang Sari display can reduce stress levels of the elderly.

Keywords : gymnastics, stress levels, the elderly PENDAHULUAN

Usia lanjut merupakan tahap akhir pada daur kehidupan manusia dan tidak bisa dipungkiri setiap manusia akan mengalami bagi yang dikaruniai usia panjang. Lansia bukan merupakan penyakit, namun merupakan tahap lanjut dari suatu proses kehidupan yang ditandai dengan penurunan kemampuan tubuh untuk beradaptasi dengan lingkungan (Efendi, 2009).

Organisasi Kesehatan Dunia (WHO) 2013, dalam Menkes RI menggolongkan lanjut usia menjadi 4 yaitu : usia pertengahan (middle age) 45 - 59 tahun, lanjut usia (elderly) 60 - 74 tahun, lanjut usia tua (old)75 - 90 tahun dan usia sangat tua (very old)diatas 90 tahun. Sedangkan kategori menurut Depkes RI 2009 masa lansia awal 46 - 55 tahun, masa lansia akhir 56 - 65 tahun dan masa manula 65 keatas.

Berdasarkan laporan United Nations Population Devision, "Life Expectancy at Birt-Both Sexes, Life Expectancy at Birt-Female, dan Life Expectancy at Birt-Male"di New York Amerika Serikat terdapat 384 juta orang lansia di dunia. Saat ini angkanya meningkat lebih dari dua kali lipat menjadi 893 juta orang lansia. Peningkatan populasi lansia di Indonesia pada tahun 2005 sebanyak 15,8 juta sekitar 7,2 \% meningkat 3 kali daripada tahun 1970 sebanyak 5,3 juta ${ }^{\mathrm{i}}$. 
Jurnal Kesehatan Karya Husada, Vol 9 No 1 Tahun 2021

PISSN 2337649X/EISSN 2655-8874

Endang Tri Sulistyowati“Penurunan Tingkat Stres Lansia dengan Senam Lansia di Dusun Mangir Tengah Pajangan Bantul” (hal 74-90)

Peningkatan jumlah penduduk lansia apabila tidak segera ditangani akan menambah masalah yang sangat komplek, terutama di bidang kesehatan mengingat lansia merupakan periode dimana fungsi tubuh telah mengalami kemunduran dan identik dengan menurunnya daya tahan tubuh dan mengalami berbagai penyakit degeneratif ${ }^{2}$. Keadaan tersebut, berpengaruh pada permasalahan yang diterima dari lingkungan sekitar, maka tekanan pada diri lansia akan sangat berpengaruh pada timbulnya stres ${ }^{3}$.

Stres sebagai reaksi fisik dan psikis yang berupa perasan tidak enak, tidak nyaman, atau tertekan akibat dari persepsi yang dianggapnya sebagai ancaman bagi keselamatan dirinya. Sedangkan stres pada lansia dapat didefinisikan sebagai tekanan yang diakibatkan oleh stresor berupa perubahan - perubahan yang menuntut adanya penyesuaian dari lansia. Tingkat stres pada lansia berarti pula tinggi rendahnya tekanan yang dirasakan atau dialami oleh lansia sebagai akibat dari stresor berupa perubahan - perubahan baik fisik, mental, maupun sosial dalam kehidupan yang dialami lansia ${ }^{4}$. - Stres yang menghampiri individu akan dipersepsikan atau akan dimaknai berbeda oleh masing-masing individu sehingga respon yang dihasilkan pun akan berbeda. Proses mempersepsi atau memaknai stresor ini melibatkan proses mental (kognisi) dan pengalaman-pengalaman individu dalam kehidupannya. Hal ini dijelaskan bahwa perbedaan usia akan mempengaruhi persepsi dan pemaknaan individu terhadap stres. Hal ini dapat dilihat pada tingkat stres orang usia lanjut atau lansia. 
Jurnal Kesehatan Karya Husada, No 9 Vol 1 Tahun 2021

PISSN 2337649X/EISSN 2655-8874

Endang Tri Sulistyowati“Penurunan Tingkat Stres Lansia dengan Senam Lansia di Dusun Mangir Tengah Pajangan Bantul" (hal 74-90)

$$
\text { Pada kesempatan kali ini Hasil wawancara dengan }
$$

penulis memberikan kegiatan senam kepala dukuh Mangir Tengah lansia sebagai pemulihan fungsional Sendangsari Pajangan Bantul, yaitu dengan cara membuat persendian diperoleh informasi jumlah penduduk otot dan kondisi tubuh umumnya yang lebih dari 60 tahun sebanyak 41 berfungsi sebagai mana mestinya orang. Hasil wawancara dengan sehingga lansia dapat memenuhi beberapa lansia didapatkan 3 lansia kebutuhan hidupnya. Senam lansia mengatakan sepi karena jauh dari adalah aktivitas yang cocok untuk anak, sedangkan 2 orang lainnya lansia karena olah raga ini mudah mengatakan tidak dapat melakukan dilakukan dan tidak memberatkan aktivitas yang dulu biasa dilakukan lansia. Aktifitas olahraga ini akan karena bertambahnya usia.

membantu tubuh agar tetap bugar dan tetap segar karena melatih tulang tetap kuat, mendorong jantung bekerja optimal daan membantu menghilangkan radikal bebas yang berkeliaran di dalam tubuh. Dengan mengikuti senam lansia efek minimalnya adalah lansia merasa gembira, bisa tidur nyenyak dan pikiran tetap segar.

$$
\text { Berdasarkan uraian di atas }
$$
penulis merasa tertarik untuk melakukan penelitian dengan judul "Pengaruh senam Lansia terhadap penurunan tingkat stres pada lansia di dusun Mangir tengah Pajangan Bantul'.Penelitian ini bertujuan untukmengetahui pengaruh senam lansia terhadap tingkat stres pada lansia. 
Jurnal Kesehatan Karya Husada, No 9 Vol 1 Tahun 2021

PISSN 2337649X/EISSN 2655-8874

Endang Tri Sulistyowati“Penurunan Tingkat Stres Lansia dengan Senam Lansia di Dusun Mangir Tengah Pajangan Bantul" (hal 74-90)

\section{TINJAUAN PUSTAKA}

Setiap orang akan mengalami

penuaan. Penuaan adalah fenomena

universal yang mengubah cadangan

fisiologis individu dan kemampuan

untuk mempertahankan homeostasis.

Apabila dilihat dari sudut pandang

yang lebih luas, proses penuaan

merupakan suatu perubahan progresif

pada organisme yang telah mencapai

kematangan intrinsik dan bersifat

irreversibel serta menunjukkan adanya

kemunduran sejalan dengan waktu.

Usia lanjut dapat dikatakan usia emas karena tidak semua orang dapat mencapai usia tersebut. Sebutan untuk orang yang berusia lanjut ada bermacam-macam antara lain manusia usia lanjut (manula), orang lajut usia (lansia), golongan lanjut umur (glamur), usia lanjut (usila), bahkan di Inggris orang menyebutnya dengan istilah warga negara senior ${ }^{5}$. Lanjut usia atau sering disingkat dengan lansia adalah seseorang yang telah mencapai usia 60 tahun keatas, baik pria maupun wanita. Lansia sendiri bukan merupakan suatu penyakit, melainkan tahap lanjut dari suatu proses kehidupan yang ditandai dengan penurunan kemampuan tubuh beradaptasi dengan stres lingkungan dan akan mengalami kemunduran baik fisik, mental dan sosial secara bertahap $^{6}$. BPS membagikelompok umur lansia menjadi lansia muda yaitu usia $60-69$ tahun, lansia menengah yaitu usia 70 - 79 tahun dan lansia tua yaitu usia 80 tahun ke atas ${ }^{1}$.

Stres merupakan suatu kondisi sesorang yang mengalami tututan emosi yang berlebih dalam waktu yang membuatnya sulit untuk memfungsikan secara efektif semua wilayah kehidupan.Keadaan ini dapat mengakibatkan munculnya cukup 
Jurnal Kesehatan Karya Husada, No 9 Vol 1 Tahun 2021

PISSN 2337649X/EISSN 2655-8874

Endang Tri Sulistyowati“Penurunan Tingkat Stres Lansia dengan Senam Lansia di Dusun Mangir Tengah Pajangan Bantul" (hal 74-90)

banyak gejala, seperti depresi, kelehan

kronis, mudah marah, gelisah dan kualitas kerja yang rendah ${ }^{7}$.

Stres adalah respon fisik terhadap peristiwa yang membuat sesorang terancam atau terganggu keseimbangannya dalam berbagai cara. Ketika seseorang merasakan bahaya, tubuh akan melakukan pertahanan secara otomatis, respon fisiologis ini yang mendorong seseorang untuk menyerang atau melarikan diri ${ }^{8}$. Stres adalah suatu proses yang menilai suatu peristiwa sebagai sesuatu yang mengancam, ataupun yang membahayakan dan individu merespon peristiwa itu pada level fisiologis, emosional, kognitif, dan perilaku ${ }^{7}$.

Penggolongan ini didasarkan atas persepsi individu terhadap stres yang dialami, yaitu :

a. Distress (stres negatif)
Distress merupakan respon terhadap kejadian-kejadian negatif seperti kematian anak, istri, di PHK dari pekerjaan, termasuk di dalamnya jika orang tua memiliki anak yang menderita autis yang juga merupakan cobaan berat

\section{a. Eustress (stres positif)}

Eustress bersifat menyenangkan dan merupakan pengalaman yang memuaskan., seperti mendapatkan kenaikan jabatan.

Stres diklompokkan menjadi 3 tingkat $^{9}$

a. Stres ringan

Stres tingkat ini terjadi di kehidupan sehari-hari dan dapat membantu individu menjadi waspada dan mencegah berbagai kemungkinan yang dapat terjadi.

a. Stres sedang

Pada tingkat stres ini individu lebih memfokuskan pada hal penting dan 
Jurnal Kesehatan Karya Husada, No 9 Vol 1 Tahun 2021

PISSN 2337649X/EISSN 2655-8874

Endang Tri Sulistyowati“Penurunan Tingkat Stres Lansia dengan Senam Lansia di Dusun Mangir Tengah Pajangan Bantul" (hal 74-90)

mengesampingkan yang lainnya Gejala fisik dapar berupa : nyeri sehingga mempersempit lahan kepala dan punggung, diare dan

persepsinya.

b. Stres berat

Pada tingkat ini, persepsi individu sangat menurun dan cederung memusatkan perhatian pada hal-hal lain dan memerlukan banyak pengarahan.

Tanda-tanda individu yang mengalami stres $^{8}$, yaitu :

\section{a. Gejala Kognitif}

Gejala kognitif meliputi masalah dalam memori, sulit konsentrasi, sulit mengambil keputusan, selalu berpandangan negatif, cemas, ketakutan yang berlebihan dan lainlain.

\section{b. Gejala Emosional}

Gejala emosional antara lain : murung, agitasi, cepat marah, rasa kesepian, depresi dan tidak bahagia.

c. Gejala fisik sembelit, mual dan pusing, nyeri dada dan berdebar-debar, insomnia, gatagatal dan lain-lain.

d. Gejala perubahan perilaku

Gejala perubahan perilaku meliputi : makan berlebihan, atau tidak mau makan sama sekali, kurang tidur atau berlebih, menyendiri, mengalihkan ke alkohol atau narkoba.

Stres dapat diatasi dengan berbagai cara salah satunya adalah teknik relaksasi yang tujuannya untuk mengendorkan ketegangan otot-otot, karena stres mempengaruhi ketegangan otot.

Sehingga dengan dilakukannya relaksasi akan melemaskan oto-otot, maka stres akan menurun.Relaksasi dapat dicapai dengan cara mengatur nafas dengan konstan $^{10}$. 
Jurnal Kesehatan Karya Husada, No 9 Vol 1 Tahun 2021

PISSN 2337649X/EISSN 2655-8874

Endang Tri Sulistyowati“Penurunan Tingkat Stres Lansia dengan Senam Lansia di Dusun Mangir Tengah Pajangan Bantul" (hal 74-90)

Cara lain dalam mengatasi berpengaruh dalam meningkatkan stres adalah dengan berolahraga. Olah imunitas dalam tubuh manusia setelah raga dapat membantu tubuh dalam latihan teratur.

menghadapi stres. Olahraga terbukti

Olah raga dengan teratur salah dapat menurunkan kecemasan, stres, satu nya senam lansia dapat mencegah depresi dan tekanan ${ }^{11}$.

atau memperlambat kehilangan

Senam lansia adalah fungsional organ dan mengurangi serangkaian gerak nada yang teratur berbagai resiko penyakit seperti dan terarah serta terencana yang hipertensi, diabetes melitus, penyakit diikuti orang lanjut usia dengan tujuan arteri koroner, selain itu senam lansia untuk meningkatkan kemampuan sangat bermanfaat untuk menghambat fungsional raga. Senam lansia ini proses degeneratif. Dengan mengikuti dirancang secara khusus untuk melatih senam lansia efek minimalnya lansia bagian tubuh agar mendapatkan akan merasa bahagia, bisa tidur peregangan bagi lansia dengan dengan nyenyak, dan pikiran tetap gerakan yang tidak berlebihan $^{12}$.

segar, sehingga nyaman dan aman Manfaat dari senam lansia dalam menjalani hidup ${ }^{12}$.

antara lain : 1) membantu tubuh tetap Tahap dari senam lansia sebagai bugar, 2) melatih tulang tetap kuat, 3) berikut $^{13}$ :

mendorong jantung bekerja optimal.

\section{a. Gerakan pemanasan}

Senam lansia memiliki dampak positif Sikap permulaan, berdiri tegak, lainnya yaitu terhadap peningkatan menghadap ke depan kemudian fungsi organ tubuh dimana sangat mengambil nafas dengan mengangkat 
Jurnal Kesehatan Karya Husada, No 9 Vol 1 Tahun 2021

PISSN 2337649X/EISSN 2655-8874

Endang Tri Sulistyowati“Penurunan Tingkat Stres Lansia dengan Senam Lansia di Dusun Mangir Tengah Pajangan Bantul" (hal 74-90)

kedua lengan membentuk huruf $\mathrm{V}$. penelitan ini adalah lansia di dusun Gerakan ini bertujuan untuk Mangir Tengah Pajangan Bantul.

meregangkan otot dan persendian.

b. Gerakan inti

Dimulai dengan gerakan peralihan jalan, tepuk dan goyang tangan $2 \times 8$ hitungan yang bertujuan untuk penguatan dan pengencangan otot serta meningkatkan keseimbangan.

c. Gerakan pendinginan

Gerakan tahap pendinginan ini bertujuan untuk menurunkan suhu tubuh, denyut jantung dan tekanan darah, dapat dilakukan dengan gerakan berjalan pelan ${ }^{14}$.

\section{METODE PENELITIAN}

Penelitian ini merupakan penelitian Quasy Experiment dengan desain penelitian ini adalah one group pre-post testyang dilakukan diDusun Mangir Tengah kelurahan Sendangsari Pajangan Bantul. Adapun subyek
Pengambilan sampel dengan metode total sampling, yaitu semua lansia yang ada di dusun Mangir Tengah yang bersedia menjadi subyek penelitian. Jumlah lansia di Dusun Mangir sebanyak 41 orang dan yang bersedia menjadi subyek penelitian ini sebanyak 34 orang.

Instrumen penelitian

menggunakan kuesioner untuk mengukur tingkat stress lansia.Sebelum mendapat intervensi, responden di wawancarai untuk mengukur tingkat stress responden (pretest). Intervensi berupa senam dilakukan setiap dua kali selama 4 (minggu) minggu pada minggu ke 2 dan ke 4. Pada hari setelah dilakukan senam lansia, tingkat stress responden diukur (posttes I dan II) postest II diadakan setelah 2 minggu dari posttes 
Jurnal Kesehatan Karya Husada, No 9 Vol 1 Tahun 2021

PISSN 2337649X/EISSN 2655-8874

Endang Tri Sulistyowati“Penurunan Tingkat Stres Lansia dengan Senam Lansia di Dusun Mangir Tengah Pajangan Bantul" (hal 74-90)

I. Posttes diadakan untuk mengetahui

\begin{tabular}{|l|l|l|}
\hline Bekerja & 7 & 20.6 \\
\hline
\end{tabular}

dampak dari senam lansia terhadap

tingkat stress lansia.

$$
\text { Sebagian besar responden }
$$

berjenis kelamin perempuan, yaitu

sebanyak 76,5 persen dan yang leki-

\section{HASIL PENELITIAN}

Penelitian ini dilakukan terhadap 34 responden lansia diDusun Mangir

Tengah

Kelurahan

Sendangsari,Kecamatan Pajangan,

Kabupaten Bantul. Adapun

karakteristik rssponden dijelaskan dalam table berikut.

\begin{tabular}{|l|c|c|}
\hline Karakteristik & $\begin{array}{c}\text { Jumla } \\
\text { h }\end{array}$ & \% \\
\hline Jenis Kelamin & 8 & 23.5 \\
\hline Laki-laki & 26 & 76.5 \\
\hline Perempuan & 13 & 38.2 \\
\hline Umur & 17 & 50.0 \\
\hline $\begin{array}{l}\text { Lansia Muda (60- } \\
\text { 69th) }\end{array}$ & 4 & 11.8 \\
\hline $\begin{array}{l}\text { Lansia Menengah } \\
\text { (70-79th) }\end{array}$ & 3 & 8.8 \\
\hline Lansia tua (>80th) & 15 & 44.1 \\
\hline Pendidikan & 12 & 35.3 \\
\hline SD & 4 & 11.8 \\
\hline SMP & 27 & 79.4 \\
\hline SMA & \\
\hline Perguruan Tinggi & & \\
\hline Pekerjaan & & \\
\hline Tidak Bekerja & 13 & \\
\hline
\end{tabular}

laki hanya 23,5 persen. Separuh jumlah responden berusia dalam kategori lansia menengah (70-80 tahun), lansia muda sebanyak 38,2 persen dan yang berusia lansia tua sebanyak 11,8 persen.

Sebanyak 44,1 persen responden berpendidikan SLTP dan SLTA sebanyak 35,3 persen. Responden yang berpendidikan perguruan tinggi hanya 11,8 persen dan yang berpendidikan SD sekitar 8,8 persen. Hampir semua rsponden sudah tidak bekerja, hanya sekitar 20 persen responden yang masih aktif bekerja.

Tingkat stress diukur dengan instrument yang telah ditetapkan. Pengukuran tingkat stress dilakukan 3 
Jurnal Kesehatan Karya Husada, No 9 Vol 1 Tahun 2021

PISSN 2337649X/EISSN 2655-8874

Endang Tri Sulistyowati“Penurunan Tingkat Stres Lansia dengan Senam Lansia di Dusun Mangir Tengah Pajangan Bantul" (hal 74-90)

kali, yaitu pada saat sebelum

mendapat intervensi (pretest) serta

setelah 2 minggu mengukuti intervensi

senam lansia (posttes I) dan s(posttes

II). Adapun distribusi frekuensi

jumlah responden menurut tingkatan

stress pada tiga tahapan pengukuran

dijelaskan dalam table sebagai berikut

\begin{tabular}{|c|c|c|}
\hline Tingkat Stress & Jumlah & Persen \\
\hline Pretes & & \\
\hline Stres Ringan & 3 & 8.8 \\
\hline Stres Sedang & 10 & 29.4 \\
\hline Stres Berat & 21 & 61.8 \\
\hline Postes I & & \\
\hline Stres Ringan & 5 & 14.7 \\
\hline Stres Sedang & 20 & 58.8 \\
\hline Stres Berat & 9 & 26.5 \\
\hline Postes I & & \\
\hline Stres Ringan & 17 & 50.0 \\
\hline Stres Sedang & 12 & 35.3 \\
\hline Stres Berat & 5 & 14.7 \\
\hline \multicolumn{2}{|l}{} \\
\hline
\end{tabular}

Pada saat pretes jumlah responden yang mengalami stress ringan hanya sebanyak 8,8 persen. Responden yang mengalami stress tingkat sedang sebanyak 29,4 persen dan yang mengalami stress tingkat berat sebanyak 61,8 persen

Pada saat postes I, jumlah responden yang mengalami stress tingkat ringan bertambaj menjadi 14,7 persen. Responden yang mengalami stress tingkat sedang bertambah menjadi 58,8 persen dan yang mengalami stress tingkat berat berkurang menjadi 26,5 persen.

Jumlah responden yang mengalami stress ringan bertambah menjadi 50,0persen. Responden yang mengalami stress tingkat sedang berkurang menjadi 35,5 persen dan yang mengalami stress tingkat berat semakin berkurang hanya 14,7 persen.

Perbandingan Rata-rata Tingkat Stress Sebelum dan Sesudah dilakukan Intervensi

Penelitian ini dilakukan selama satu bulan. Senam lansia diadakan seminggu sekali pada hari minggu 
Jurnal Kesehatan Karya Husada, No 9 Vol 1 Tahun 2021

PISSN 2337649X/EISSN 2655-8874

Endang Tri Sulistyowati“Penurunan Tingkat Stres Lansia dengan Senam Lansia di Dusun Mangir Tengah Pajangan Bantul" (hal 74-90)

pagi. Sebelum mendapat intervensi

senam lansia, responden diwawancarai untuk mengetahui tingkat stressnya.

Pengukuran tingkat stress responden untuk mengetahui dampak senam lansia terhadap tingkat stress responden dilakukan 2 kali yaitu pada minggu ke 2 dan minggu ke 4. Hasil pengukuran tersebut dibandingkan untuk mengetahui dampak dari senam lansia terhadap tingkat stress lansia seperti dijelaskan dalam table berikut.

\begin{tabular}{|c|c|c|c|c|c|}
\hline $\begin{array}{c}\text { Wa } \\
\text { ktu } \\
\text { Pen } \\
\text { guk } \\
\text { ura } \\
\text { n }\end{array}$ & $\begin{array}{c}\text { Rat } \\
\text { a- } \\
\text { rata } \\
\text { Sko } \\
\text { r } \\
\text { Stre } \\
\text { sS }\end{array}$ & SD & $\begin{array}{c}\text { Selis } \\
\text { ih }\end{array}$ & $\mathbf{t}$ & p \\
\hline $\begin{array}{l}\text { Pret } \\
\text { es }\end{array}$ & $\begin{array}{c}29.0 \\
6\end{array}$ & $\begin{array}{c}8.19 \\
4\end{array}$ & $\begin{array}{c}6.67 \\
6\end{array}$ & $\begin{array}{l}5.0 \\
57 \\
\end{array}$ & \\
\hline $\begin{array}{l}\text { Post } \\
\text { es I }\end{array}$ & $\begin{array}{c}22.3 \\
8\end{array}$ & $\begin{array}{c}7.91 \\
2 \\
\end{array}$ & & & \\
\hline $\begin{array}{l}\text { Post } \\
\text { es I }\end{array}$ & $\begin{array}{c}22.3 \\
8\end{array}$ & $\begin{array}{c}7.91 \\
2\end{array}$ & $\begin{array}{c}6.58 \\
8\end{array}$ & $\begin{array}{l}5.4 \\
13\end{array}$ & \\
\hline $\begin{array}{l}\text { Post } \\
\text { es II }\end{array}$ & $\begin{array}{c}15.7 \\
9\end{array}$ & $\begin{array}{c}8.54 \\
1\end{array}$ & & & \\
\hline $\begin{array}{l}\text { Pret } \\
\text { es }\end{array}$ & $\begin{array}{c}29.0 \\
6\end{array}$ & $\begin{array}{c}8.19 \\
4\end{array}$ & $\begin{array}{c}13.2 \\
65\end{array}$ & $\begin{array}{l}7.7 \\
69\end{array}$ & $\begin{array}{l}0.0 \\
00\end{array}$ \\
\hline
\end{tabular}

\begin{tabular}{|l|c|c|l|l|l|}
\hline Post & 15.7 & 8.54 & & & \\
es II & 9 & 1 & & & \\
\hline
\end{tabular}

Ada perbedaan rata-rata skor tingkat stress pada saat pretes dengan postes I secara signifikan $(\mathrm{p}<0,05)$ berdasarkan paired t-test. Rata-rata skor tingkat stress pada saat pretes sebesar 29,06 menurun menjadi 22,38 dengan selisih 6.676. Hal tersebut dapat dimaknai bahwa setelah dilakukan 2 minggu, senam lansia menurunkan tingkat stress lansia.

Rata-rata skor tingkat stress pada saat postes I sebesar 22,38 dan berkurang 6.59menjadi 15.79 pada postes II. Hasil

uji statistic menunjukkan bahwa perbedaan rata-rata tersebut signifikan $(p<0,05)$. Hal tersebut dapat dimaknai bahwa setelah dilakukan 4 minggu, 
Jurnal Kesehatan Karya Husada, No 9 Vol 1 Tahun 2021

PISSN 2337649X/EISSN 2655-8874

Endang Tri Sulistyowati“Penurunan Tingkat Stres Lansia dengan Senam Lansia di Dusun Mangir Tengah Pajangan Bantul" (hal 74-90)

senam lansia semakin menurunkan

tingkat stress lansia.

Secara keseluruhan, Rata-rata skor tingkat stress pada saat pretes sebesar 29,06 menurun menjadi 15.79 pada postes II dengan selisih 13.265. Hal tersebut dapat dimaknai bahwa setelah dilakukan 4 minggu, senam lansia menurunkan tingkat stress lansia sekitar 44 persen.

\section{PEMBAHASAN}

Senam lansia bertujuan untuk relaksasi otot. Stress menyebabkan ketegangan otot. Dengan melakukan senam lansia secara rutin dan teratur diharapkan ketegangan otot menurun sehingga tubuh menjadi bugar dan lebih rileks. Senam lansia memang dirancang secara khusus untuk melatih bagian tubuh agar mendapatkan peregangan atau relaksasi bagi lansia dengan gerakan yang tidak berlebihan $^{12}$.
Hasil penelitian ini menunjukkan bahwa jumlah responden yang mengalami stress berat berkurang setelah kelompok lansia yang menjadi responden penelitian melakukan senam. Hasil uji paired t-test juga menunjukkan bahwa terjadi penurunan skor stress sebesar 13,265 dan signifikan secara statistic $(\mathrm{p}<0,05)$ setelah responden mengikuti senam lansia secara rutin setiap minggu. Senam lansia mempunyai efek minimal berupa lansia merasa bahagia, bisa tidur dengan nyenyak, dan pikiran tetap segar, sehingga nyaman dan aman dalam menjalani hidup ${ }^{12}$. Efek tersebut yang menyebabkan stress lansia mengalami penurunan.Senam lansia dilakukan secara berkelompok juga memberikan dampak yang positif terhadap tingkat stress lansia, karena lansia dapat bersosialisasi dengan lansia lainnya. Hasil penelitian 
Jurnal Kesehatan Karya Husada, No 9 Vol 1 Tahun 2021

PISSN 2337649X/EISSN 2655-8874

Endang Tri Sulistyowati“Penurunan Tingkat Stres Lansia dengan Senam Lansia di Dusun Mangir Tengah Pajangan Bantul" (hal 74-90)

sebelumnya menemukan bahwa lansia

yang merasakan adanya gejala depresi

mengatakan bahwa saat ini hanya

tinggal bersama pasangan, karena

anggota keluarganya telah berumah

tangga dan memiliki kesibukan

masing-masing sehingga hampir tidak

pernah berkumpul bersama ${ }^{15}$.

Hasil penelitian ini serupa dengan

hasil penelitian sebelumnya yang

menemukan bahwa terdapat perbedaan

yang bermakna antara skor Geriatric

Depression Scale (GDS) sebelum dan

sesudah perlakuan senam lansia ${ }^{16}$.

Skor GDS setelah perlakuan senam

lansia lebih rendah dibandingkan

sebelum perlakuan.Olah raga dengan

teratur dapat mencegah atau

memperlambat kehilangan fungsional

organ dan mengurangi berbagai resiko

penyakit seperti hipertensi, diabetes

melitus, penyakit arteri koroner, selain

itu senam lansia sangat bermanfaat untuk menghambat proses degeneratif $^{12}$. Oleh karenanya, kegiatan senam lansia secara rutin berkala setiap minggu di Dusun Mangir Tengah, Sendangsari, Pajangan, Bantul perlu dipertahan agar kesehatan fisik dan mental lansia dapat terjaga.

Kegiatan tersebut juga dapat digunakan sebagai media komunikasi antar lansia di dusun tersebut agar stressor lansia dapat diminimalkan karena lansia dapat berkumpul dan berkomunikasi dengan sesama lansia $^{17}$. Rasa kesepian dan tidak berguna seringkali muncul dari kurangnya aktivitas, apabila dibiarkan secara terus-menerus maka maka akan berdampak negatif bagi lansia. Kegiatan senam lansia juga dapat dimanfaatkan oleh kepala dukuh atau pihak stake holder lain sebagai media memantau kesehatan lansia. 
Jurnal Kesehatan Karya Husada, No 9 Vol 1 Tahun 2021

PISSN 2337649X/EISSN 2655-8874

Endang Tri Sulistyowati“Penurunan Tingkat Stres Lansia dengan Senam Lansia di Dusun Mangir Tengah Pajangan Bantul" (hal 74-90)

Keterbatasan penelitian penelitian ini adalah variable pengganggu seperti penyakit, tingkat sosial ekonomi, dukungan keluarga dan sebagainya tidak dikontrol, sehingga penurunan tingkat stress dalam penelitian kemungkinan juga disebabkan oleh factor stressor yang menurun.

Penelitian ini mengamati kegiatan senam lansia yang dilakukan secara bersama-sama, sehingga pengamatan yang dilakukan adalah pengamatan secara utuh kegiatan senam lansia bersama. Penurunan tingkat stress responden dapat disebabkan oleh kebersamaan dan/atau akibat senam yang dilakukan.

\section{KESIMPULAN}

Hasil penelitian ini dapat disimpulkan bahwa kegiatan senam lansia yang dilakukan secara bersama-sama di Dusun Mangir Tengah, Sendangsari,
Pajangan, Bantul dapat menurunkan tingkat stress lansia setelah dilakukan secara rutin setiap minggu selama satu bulan. Penurunan tingkat stress lansia setelah melakukan senam lansia bersama sekitar 44 persen. Semula rata-rata tingkat stress lansia di dusun Mangir tengah sebesar 29,06setelah mengikuti senam lansia selama satu bulan tingkat stress lansia menjadi 15.79 .

\section{SARAN}

Kegiatan senam lansia dapat dilanjutkan sebagai kegiatan rutin mingguan di posyandu lansia di Dusun Dusun Mangir Tengah, Sendangsari, Pajangan, Bantul

\section{REFERENSI}

1. Badan Pusat Statistik Jakarta Pusat. 2010. Statistik Indonesia Tahun 2010. Jakarta Pusat ; Badan Pusat Statistik. 
Jurnal Kesehatan Karya Husada, No 9 Vol 1 Tahun 2021

PISSN 2337649X/EISSN 2655-8874

Endang Tri Sulistyowati“Penurunan Tingkat Stres Lansia dengan Senam Lansia di Dusun Mangir

Tengah Pajangan Bantul" (hal 74-90)

2. Maryam. 2008. Mengenal Usia

Lanjut dan Perawatannya. Jakarta

: Salemba Medika

3. Rosita. 2012. Pengaruh komitmen

Organisasi terhadap kepuasan

Kerja Dengan Role Stres sebagai

Veriabel Moderating. JAAI Vol

12 No 1

4. Indriana, 2010. Ragam Alat Bantu

Media Pengajaran. Jogjakarta :

Diva Perss

5. (Maryam, dkk 2011)

6. Kushariyadi. 2011. Asuhan

Keperawatan Pada Klien Lanjut

Usia.Jakarta : Salemba Medika

7. Ricard. 2010. Era Baru

Manajemen. Edisi 9 Buku 2.

Jakarta : Salemba Empat

8. Smith. 2011. Health Psychology:

Biopsychososial interactional

officers : A literature Review.

International Journal of Stress

Management 7

9. Maramis. 2009. Catatan Ilmu

Kedokteran Jiwa. Surabaya :

Airlangga

10. Wortman. 2010. Psychology. Five

Edition. USA : Mc. Graw Hill, Inc.
11. Sasongko. 2011. Kebisingan Lingkungan. Semarang: Univ. Diponegoro

12. Setiawan.2012. Pengembangan Pembelajaran Aktif dengan ICT. Yogyakarta : Skripta Media Creative

13. Dirjen Bina Kesejahteraan Sosial RI. 2000. Buku Pedoman Karang

Taruna. Jakarta : Menpora

14. Suroto. 2010. Pegangan Kuliah : Pengertian Senam, Manfaat Senam dan Urutan Gerakan. Semarang : Universitas Diponegoro

15. Parasari GAT dan Lestari MD(2015) Hubungan Dukungan Sosial Kkeluarga dengan Tingkat Depresi pada Lansia di Kelurahan Sading, Jurnal Psikologi Udayana, Vol. 2, No. 1, 68-77

16. Sujana D, WardaniND dan Jusup I, Pengaruh Senam Lansia Terhadap Skor Geriatric Depression Scale (Studi Pada Lansia Di Posyandu Lansia Rw X Kelurahan Padangsari Kecamatan Banyumanik Kota Semarang), MMM, Vol. 4 No. 4 Oktober : 600-608 
Jurnal Kesehatan Karya Husada, No 9 Vol 1 Tahun 2021

PISSN 2337649X/EISSN 2655-8874

Endang Tri Sulistyowati“Penurunan Tingkat Stres Lansia dengan Senam Lansia di Dusun Mangir Tengah Pajangan Bantul" (hal 74-90)

17. Suardiman, S. P. (2011).

Psikologi Usia Lanjut.

Yogyakarta : Gajah Mada

University Press. 